\title{
Flexural Properties of PVC/Bamboo Composites under Static and Dynamic-Thermal Conditions: Effects of Composition and Water Absorption
}

\author{
Shahril Anuar Bahari, ${ }^{1}$ Warren J. Grigsby, ${ }^{2}$ and Andreas Krause ${ }^{3}$ \\ ${ }^{1}$ Department of Wood Biology and Wood Products, Faculty of Forest Sciences and Forest Ecology, Georg-August-Universität Göttingen, \\ Büsgenweg 4, 37077 Göttingen, Germany \\ ${ }^{2}$ Manufacturing and Bioproduct Development, Scion, Rotorua 3046, New Zealand \\ ${ }^{3}$ Centre for Wood Science, Hamburg University, Leuschnerstraße 91, 21031 Hamburg, Germany
}

Correspondence should be addressed to Warren J. Grigsby; warren.grigsby@scionresearch.com

Received 1 March 2017; Revised 28 April 2017; Accepted 1 June 2017; Published 5 July 2017

Academic Editor: Jan-Chan Huang

Copyright (C) 2017 Shahril Anuar Bahari et al. This is an open access article distributed under the Creative Commons Attribution License, which permits unrestricted use, distribution, and reproduction in any medium, provided the original work is properly cited.

Polyvinyl chloride (PVC)/bamboo composites have been prepared and assessed for their use in interior and exterior loadbearing applications. PVC composites were formed by compounding PVC with different bamboo particle sizes and loadings. The mechanical properties of these composites were determined at both ambient and elevated temperatures and after long-term water soaking. Analysis revealed that bamboo incorporation improved the PVC composite flexural modulus which was also observed with dynamic mechanical-thermal analysis on heating composites to $c a .70^{\circ} \mathrm{C}$. Addition of $25 \%$ and $50 \%$ bamboo particles increases flexural modulus by $80 \%$ with dependency on whether fine $(<75 \mu \mathrm{m})$ or coarse $(<1 \mathrm{~mm})$ particles were used. On water soaking to saturation, composites had water weight uptakes of $10 \%$, with reduced flexural properties obtained for all water-soaked composites. Nonetheless, the results of this study show that PVC/bamboo composites achieve the minimum flexural performance of ASTM D 6662 , indicating potential for their use in exterior applications.

\section{Introduction}

Thermoplastic composites filled with calcium carbonate, talc, and glass fiber fillers are typically employed across several industrial sectors. Substitution of these man-made fillers with natural materials is an emerging option for this type of composite, gaining global interest in recent years, especially in the construction, automotive, and consumer goods sectors [1]. Use of natural particles from forestry or agricultural resources as filler materials in thermoplastic composites is attractive in reducing the use of fossil fuel-based materials [2]. However, typically, the performance of thermoplasticnatural filler composites varies considerably due to variations in chemical, physical, and filler microstructure properties. Despite such variations, these composites are less abrasive on processing tools and light weight and potentially offer biodegradable products when compared to man-made material-filled thermoplastic composites [1].

Bamboo, sourced from both forest and agricultural sectors, is a potential filler material for utilization in thermoplastic composites. Bamboo is from the family of Gramineae (grass) and subfamily of Bambusoideae [3]. It is available worldwide and grows in tropical areas as well as in subtropical and temperate zones. Globally, the total bamboo area is $c a .36$ million hectares and distributed between the latitudes of $46^{\circ} \mathrm{N}$ and $47^{\circ} \mathrm{S}$ and up to 3000 meters above sea level [3]. Bamboo is a renowned fast growing plant with a short maturation period and, being widely available in Asia, is considered relatively cheap compared to other forest resources [4]. Bamboo is extensively utilized in the woodbased composites sectors, particularly in China and India 
[5], therefore offering a potential source for bamboo particle waste streams.

Arguably, bamboo particle use with thermoplastics is still in an initial phase of investigation. With commercial thermoplastics such as polypropylene (PP) and polyethylene (PE) being widely used [6], bamboo-based composites have been formed with bamboo fibers mixed with these plastics [7-10]. However, for the third-most used plastic polyvinyl chloride (PVC) [11], only a few studies have focused on PVC composites formed with chemically modified bamboo particles [12-14]. PVC thermoplastic properties can be readily modified through addition of fillers and additives to enhance performance including flexibility, elasticity, and impact resistance [11]. Adding a natural material to PVC not only serves as composite filler but also reduces polymer use with a possibility of increasing properties such as stiffness, strength, and thermal stability [15].

In the present study, PVC composites based on bamboo (Bambusa vulgaris) particle incorporation have been evaluated. These composites have been assessed for their potential in load-bearing applications, as the mechanical properties of analogous wood plastic composites (WPCs) can be comparable to wood-based products [16]. PVCbamboo composites and those subject to extensive water soaking have been assessed for mechanical and viscoelasticity properties at both ambient and elevated temperatures. The influences of differing $B$. vulgaris particle size, particle loading, and processing lubricant content levels were determined to understand the impacts of these processing variables on composite performance.

\section{Materials and Methods}

2.1. Materials Preparation. Polyvinyl chloride (PVC, Kvalue of 63) powder was sourced from Solvin SA. Bamboo particles were produced by milling the $B$. vulgaris culms, which had been harvested from a natural bamboo stand in Raub, Malaysia. Two groups of particle sizes were produced: $<75 \mu \mathrm{m}$ and $<1 \mathrm{~mm}$, being classed as small and large particles, respectively. Commercial additives were sourced as powders and include processing aids, stabilizers, and lubricants. These were stabilizer Mark CZ2000 (Chemtura, Philadelphia, USA), processing aid Paraloid K120 (Dow Chemical Co., Michigan, USA), internal lubricant Loxiol G60 (Emery Oleochemicals, Cincinnati, USA), external lubricant Loxiol G21 (Emery Oleochemicals, Cincinnati, USA), external lubricant Ligalub GT (Peter Greven Fettchemie GmbH, Bad Münstereifel, Germany), and external lubricant Licocene PE4201 (Clariant, Muttenz, Switzerland) and were variously used for composites production.

2.2. Composite Fabrication. The composites formulation (compositions) and production method were based on PVC/wood composites reported by Müller et al. [18]. B. vulgaris particles from each sieve size group were dryblended with PVC and powder additives in parts per hundred (pph, Table 1) using a hot-cool mixer (Reimelt Henschel, FM L $30 \mathrm{KM} 85$ ). The loading ratios of $B$. vulgaris particle: PVC in the hot-cool mixer were $25: 75 \mathrm{w} / \mathrm{w} \%$ and $50: 50 \mathrm{w} / \mathrm{w} \%$, in accordance with the successful production of low lubricant concentrated $\mathrm{PVC} / \mathrm{bamboo}$ composites using $1.2 \mathrm{pph}$ of dicarboxylic acid ester (internal lubricant) and $0.15 \mathrm{pph}$ of polyethylene wax (external lubricant) [17], together with additional lubricant contents level used in the present paper. The concentrations of lubricants were increased: $3.6 \mathrm{pph}$ for dicarboxylic acid ester (internal lubricant) and $0.45 \mathrm{pph}$ for polyethylene wax (external lubricant). Composition 1 $\left(\mathrm{C}_{1}\right)$ and composition $2\left(\mathrm{C}_{2}\right)$ were designated as low and high contents of these additive ingredients. The blending temperature was $120^{\circ} \mathrm{C}$ for the hot section and $40^{\circ} \mathrm{C}$ for the cool section of the mixer.

The dry-blended powders were further compounded by counterrotating double screw extrusion (Leistritz Micro 27 $40 \mathrm{D})$ at $180^{\circ} \mathrm{C}$ and $90 \mathrm{rpm}$ screw rotation to produce granules. The granules were then compressed into molded boards at $190^{\circ} \mathrm{C}$ and 60 bar pressure using a hydraulic press with 5minute pressing cycle. The dimension of the molding frame was $340 \times 280 \times 4 \mathrm{~mm}$. After the completion of the pressing cycle, the composites boards were allowed to cool before being released.

Pure PVC (without B. vulgaris particle) composites using $\mathrm{C}_{1}$ composition were also prepared using the same processing procedures. Composite board samples were cut into samples for static flexural and dynamic mechanical-thermal analysis (DMTA). All samples were conditioned at $23^{\circ} \mathrm{C}$ temperature and $50 \%$ relative humidity in a controlled conditioning room before testing. Additionally, water-soaked samples which were prepared with $C_{1}$ composition were also utilized in static flexural and DMTA testing. Water-soaked samples (80 $\times 10 \times 4 \mathrm{~mm}$ ) were cut from long-term water uptake testing (60 days) samples which had been completed prior to this mechanical testing. While being described as water-soaked samples, these had been oven-dried for at least 2 days prior to testing.

2.3. Static Flexural Testing. Static property testing was undertaken in a 3-point static flexural test using a universal testing machine model Zwick/Roell (Z010 Allround Line) equipped with Test Expert II software and $10 \mathrm{kN}$ load cell. This test was conducted on original and water-soaked $\left(C_{1}\right.$ only) composites $(80 \times 10 \times 4 \mathrm{~mm})$ at ambient temperature. Average static flexural modulus and flexural rupture testing were undertaken according to ASTM D 6662. Results are reported as an average of at least 5 replicate samples.

2.4. Dynamic Mechanical-Thermal Analysis. DMTA was conducted in 3-point flexural mode using a dynamic analyzer TA instrument RSA-G2. Testing was conducted on original $\left(\mathrm{C}_{1}\right.$ and $\mathrm{C}_{2}$ ) and water-soaked $\left(\mathrm{C}_{1}\right.$ only) composites samples ( 40 $\times 10 \times 4 \mathrm{~mm}$ ). Samples were heated at a rate of $3^{\circ} \mathrm{C} / \mathrm{min}$ from ambient temperature to $110^{\circ} \mathrm{C}$ employing $1 \mathrm{~Hz}$ frequency and $0.05 \%$ strain.

\section{Results and Discussion}

3.1. Static Flexural Properties. A range of PVC-bamboo composites were prepared varying in bamboo content and processing additives (Tables 1 and 2). Shown in Figure 1 
TABLE 1: Composition of PVC, additives, and 50\% B. vulgaris particles for the dry-blend process.

\begin{tabular}{lcrr}
\hline \multirow{2}{*}{ Raw material } & \multirow{2}{*}{ Function } & \multicolumn{2}{c}{ Parts per hundred (pph) } \\
& & $\mathrm{C}_{1}$ & $\mathrm{C}_{2}$ \\
\hline PVC $($ K value $=63)$ & Matrix & 100 & 100 \\
Calcium/zinc & Stabilizer & 2.5 & 2.5 \\
Acrylic acid & Processing aid & 1.0 & 1.0 \\
Dicarboxylic acid ester & Internal lubricant & 1.2 & 3.6 \\
Fatty acid & External lubricant & 0.2 & 0.2 \\
Glycerol ester & External lubricant & 1.2 & 1.2 \\
Polyethylene wax & External lubricant & 0.15 & 0.45 \\
\hline B. vulgaris particles & Filler & 106.25 & 108.95 \\
\hline
\end{tabular}

Note: $\mathrm{C}_{1}=$ composition $1 ; \mathrm{C}_{2}=$ composition 2 .

TABLE 2: A comparison between original and water-soaked composites in terms of static flexural properties (both from composition $\mathrm{C}_{1}$ ).

\begin{tabular}{lcr}
\hline Composites & Static flexural modulus (MPa) & Static flexural rupture (MPa) \\
\hline PVC & $2866(44)^{*}$ & $73(5)^{*}$ \\
\hline $75 \mu \mathrm{m}, 25 \%$ & $3821(193)^{*}$ & $57(4)^{*}$ \\
$75 \mu \mathrm{m}, 50 \%$ & $5115(136)^{*}$ & $47(4)^{*}$ \\
$1 \mathrm{~mm}, 25 \%$ & $4086(186)^{*}$ & $60(7)^{*}$ \\
$1 \mathrm{~mm}, 50 \%$ & $5146(204)^{*}$ & $41(4)^{*}$ \\
\hline WS, $75 \mu \mathrm{m}, 25 \%$ & $3516(144)$ & $49(1)$ \\
WS, $75 \mu \mathrm{m}, 50 \%$ & $4040(32)$ & $38(2)$ \\
WS, $1 \mathrm{~mm}, 25 \%$ & $3444(52)$ & $51(1)$ \\
WS, $1 \mathrm{~mm}, 50 \%$ & $3572(100)$ & $35(3)$ \\
\hline
\end{tabular}

${ }^{*}$ Cited from Bahari and Krause 2016.

Note: WS = water-soaked, standard deviations in parentheses.

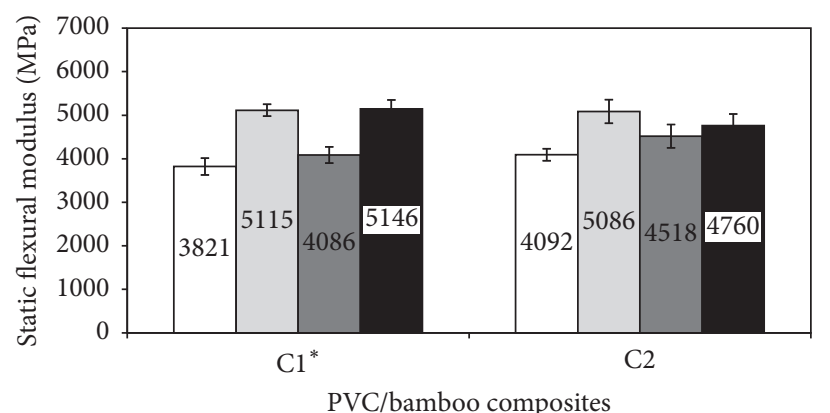

ㅁ $75 \mu \mathrm{m}, 25 \%$

ㅁ $75 \mu \mathrm{m}, 50 \%$

$1 \mathrm{~mm}, 25 \%$

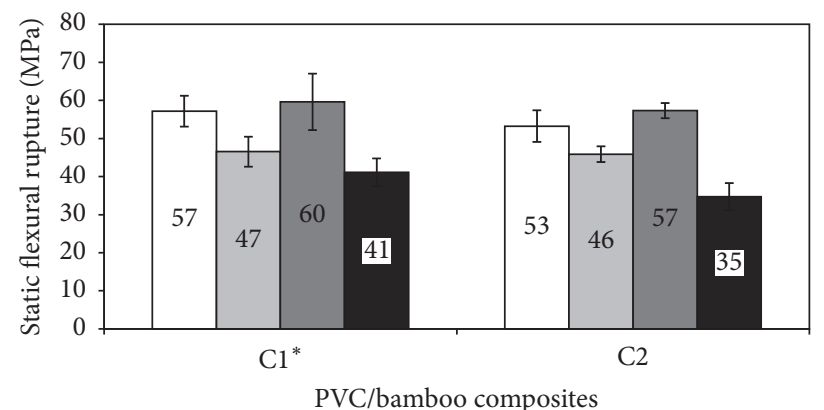

- $1 \mathrm{~mm}, 50 \%$

ㅁ $75 \mu \mathrm{m}, 25 \%$

$75 \mu \mathrm{m}, 50 \%$

$1 \mathrm{~mm}, 25 \%$

(a)

(b)

FIGURE 1: Static flexural properties of PVC/bamboo composites with different particle size, particle loading ratio, and lubricant content level; (a) mean static flexural modulus and (b) mean static flexural rupture (pure PVC has values $2866 \mathrm{MPa}$ and $73 \mathrm{MPa}$ for modulus and rupture, resp.) ( ${ }^{*}$ Bahari and Krause 2016).

are static flexural properties of PVC/bamboo composites prepared with $\mathrm{C}_{1}$ and $\mathrm{C}_{2}$ compositions. Compared to pure PVC (2866 MPa), higher flexural modulus was evident with greater bamboo particle content. The PVC/bamboo composites with $50 \%$ bamboo particle loading had a flexural modulus of $c a$. $5120 \mathrm{MPa}$ compared to $3820 \mathrm{MPa}$ for the composites with $25 \%$ particle content. For the $25 \%$ bamboo composite samples, the flexural modulus increases were up to $43 \%$ higher than pure PVC and $80 \%$ for composites with $50 \%$ particle content (Table 2). These flexural moduli 


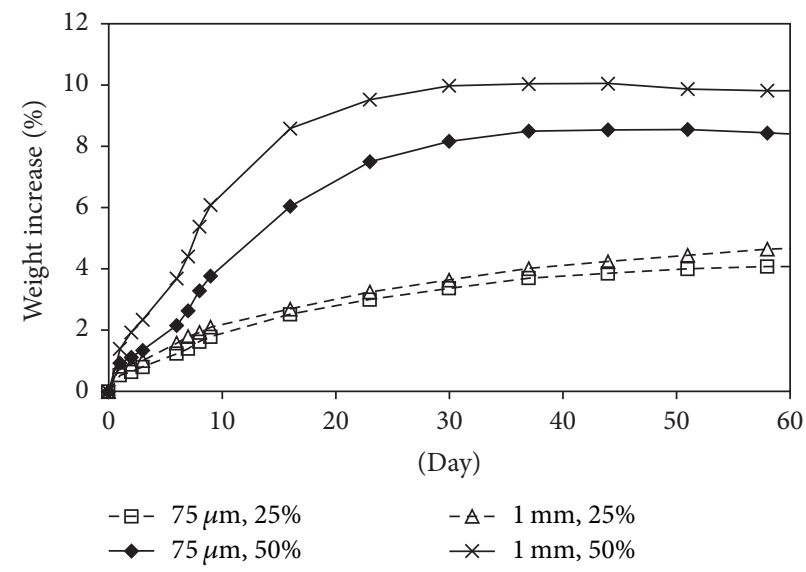

Figure 2: Long-term (60 days) water uptake of PVC/bamboo composites $\left(\mathrm{C}_{1}\right)$ using different bamboo particle sizes and loading [17].

increases are common in natural filler-polymer composites with bamboo particles contributing a $23 \%$ increase in stiffness of PP composites [7] and being similar to wood particles [19].

While increased composite stiffness is observed, incorporating bamboo particles with PVC generally reduced flexural rupture values (Figure 1). Across the composite samples, this reduction in flexural rupture was up to $39 \%$ (35 MPa, $\mathrm{C}_{2}, 1 \mathrm{~mm}$ particles with $50 \%$ bamboo content). A greater bamboo content lowered flexural rupture, but values appear independent of particle size and additives. Decreasing PVC flexural rupture was also observed on combining wood particles with similar decreases (30\%) across $35-60 \%$ wood contents [20]. The observation of decreased modulus of rupture in composites has been attributed to the interphase between the natural particle and matrix [21], dispersion and wetting of the particles [20], and, in the case of bamboo, decreasing strength of the composites due to irregularly shaped particles and stress transfer from the plastic matrix [7].

Across the different combinations of lubricant concentrations and bamboo particle size, there was relatively minimal impact to flexural properties of PVC composites (Table 2). Changing lubricant concentration had no effect on the static flexural modulus, but, arguably, a lower lubricant content $\left(\mathrm{C}_{1}\right)$ provided improved flexural rupture values compared to $\mathrm{C}_{2}$ composites containing higher lubricant content. It was likely that matrix plasticization induced by the lubricant lessened the interaction between bamboo particle and PVC matrix [14] with this effect of reduced particle interaction being exaggerated at $50 \%$ particle content for the $\mathrm{C}_{2}$ sample. While Kociszewski et al. [22] reported that PVC/wood composites with large particles have enhanced flexural modulus (11\%), in the current study, there was little impact of the bamboo particle size on this composite property. On comparing $75 \mu \mathrm{m}$ and $1 \mathrm{~mm}$ particle sizes, the use of the larger particles increased flexural modulus values by $c a$. $7 \%$ and $<1 \%$ with 25 and 50\% particle loading, respectively. Any benefit in using larger wood particles to improve particle-matrix stress transfer and enhance flexural rupture values [22] was not observed in this current study using bamboo particles.
To initially assess their potential for exterior applications, $\mathrm{PVC} /$ bamboo composite samples were immersed in water prior to testing. Based on water uptake profiles (Figure 2), composite samples can rapidly absorb water before approaching saturation on extended soaking. Typically, for composites with $25 \%$ bamboo, there was a gradual increase in sample weight for the first 10-20 days before achieving a maximum of $c a$. $4 \%$ weight gain after 50 days. In contrast, with $50 \%$ bamboo content, the water absorption was relatively rapid in the first 20 days, before reaching saturation at $c a$. $10 \%$ weight gain after 30 days. Unsurprisingly, the water-soaked composites were revealed to have significantly lower flexural properties compared to the original composites (Table 2), with up to $30 \%$ reduced flexural modulus. Within the water-soaked composites series, samples containing $1 \mathrm{~mm}$ bamboo particles have similar flexural modulus values ( $c a$. $3500 \mathrm{MPa}$ ) with any influence of particle content considered relatively small. In the case of $75 \mu \mathrm{m}$ bamboo particles, water soaking also gave a flexural modulus of $3500 \mathrm{MPa}$ at $25 \%$ bamboo content, whereas the $50 \%$ bamboo sample value was $4040 \mathrm{MPa}$. Flexural rupture values were also reduced on water soaking with samples containing $25 \%$ bamboo particles having $c a .50 \mathrm{MPa}$ compared to $c a .35 \mathrm{MPa}$ at $50 \%$ content. As happens with PVC composites containing wood furnish, this water soaking contributed to particle swelling, together with a likelihood of particle-matrix debonding [23] and microcracking within the brittle PVC matrix [24]. This consequently lowered the mechanical properties and overall composite performance. Furthermore, the higher water uptake (ca. 10\% weight gain, Figure 2) at 50\% bamboo content was directly attributable to the greater loss in flexural properties of these samples.

3.2. Composites Properties by DMTA. DMTA was undertaken with composites to assess any influence of bamboo particles on mechanical properties at elevated temperature (Figures 3 and 4 , resp., for $\mathrm{C}_{1}$ and $\mathrm{C}_{2}$, and Table 3 ). Analysis revealed that the storage modulus $\left(E^{\prime}\right)$ for all composites samples tended to decrease with temperature before a rapid loss in sample stiffness on heating beyond the PVC glass transition (Tg, 


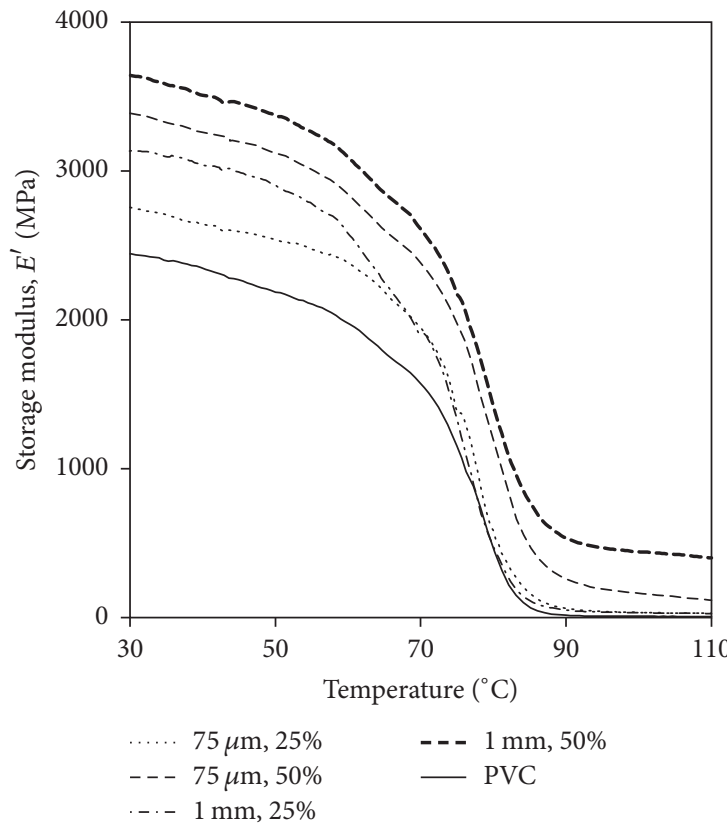

(a)

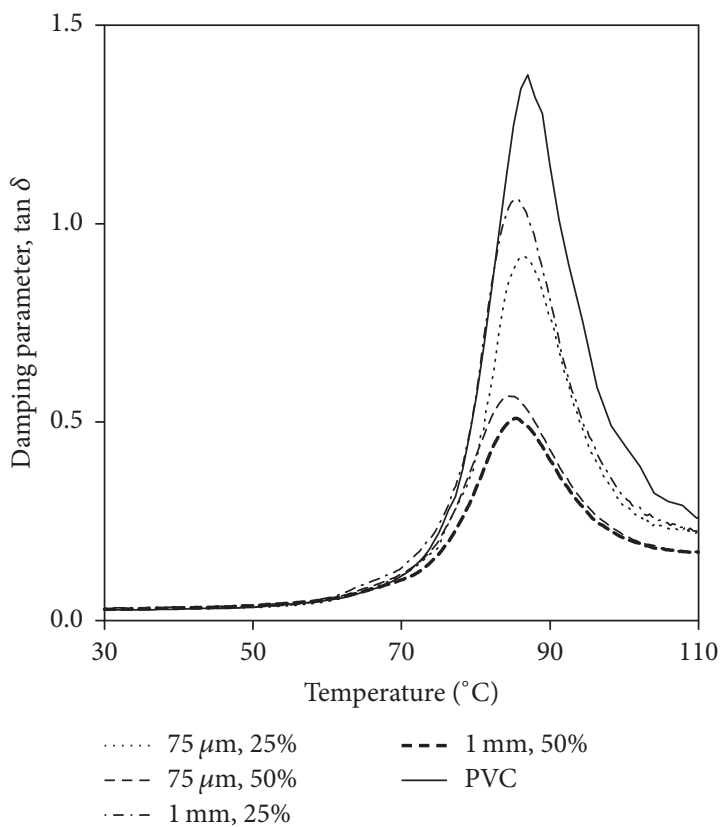

(b)

Figure 3: Typical DMTA plots of PVC/bamboo composites derived from $\mathrm{C}_{1}$, in comparison to pure PVC composites (also from $\mathrm{C}_{1}$ ): (a) storage modulus, $E^{\prime}$, and (b) $\tan \delta$.

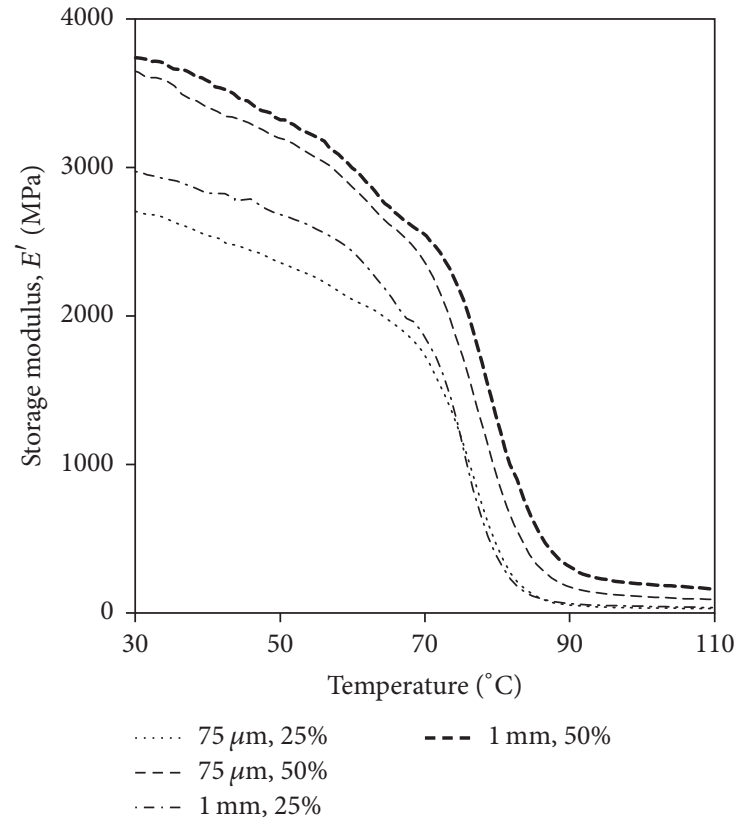

(a)

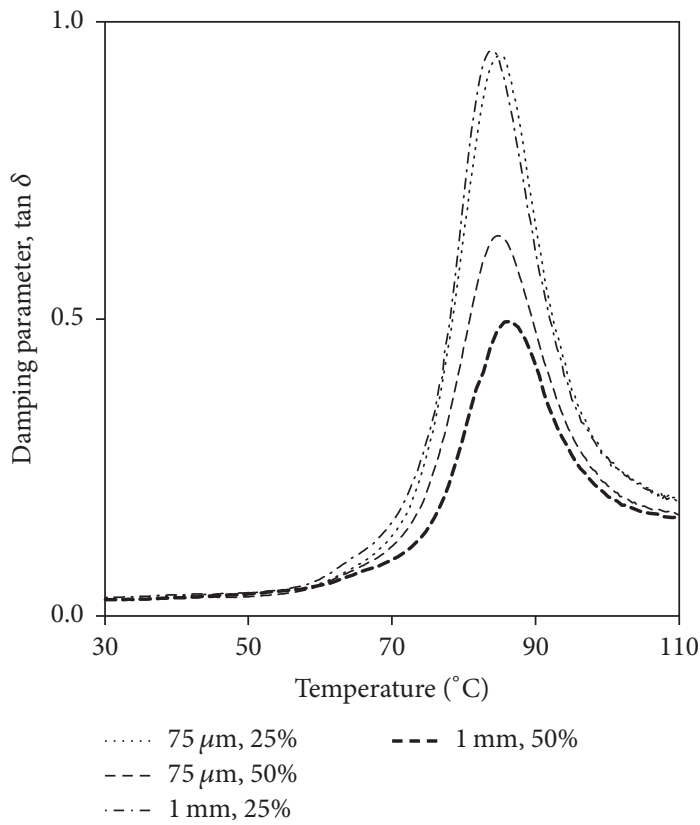

(b)

FIGURE 4: Typical DMTA plots of PVC/bamboo composites derived from $\mathrm{C}_{2}$ : (a) storage modulus, $E^{\prime}$, and (b) $\tan \delta$.

$>70^{\circ} \mathrm{C}$ ). Over the heating range $\left(30\right.$ to $\left.110^{\circ} \mathrm{C}\right)$, composites with $50 \%$ bamboo content maintain higher $E^{\prime}$ values compared to $25 \%$ bamboo with both samples being higher than pure PVC. Below the PVC Tg $\left(\right.$ ca. $\left.70^{\circ} \mathrm{C}\right), E^{\prime}$ values for $50 \%$ bamboo composites were ca. $20 \%$ higher than $25 \%$ bamboo (Table 3), consistent with flexural properties measured at ambient temperature (Figure 1 and Table 2). For the composite damping parameter $(\tan \delta)$ profiles, $\tan \delta$ maxima were observed from 84 to $90^{\circ} \mathrm{C}$ across samples. The heights of these $\tan \delta$ peaks were consistent with bamboo contents, with pure PVC being the highest (Table 3). Also apparent in Figures 3 and 4 was the similarity of DMTA profiles of the $C_{1}$ 
TABLE 3: DMTA properties of composites.

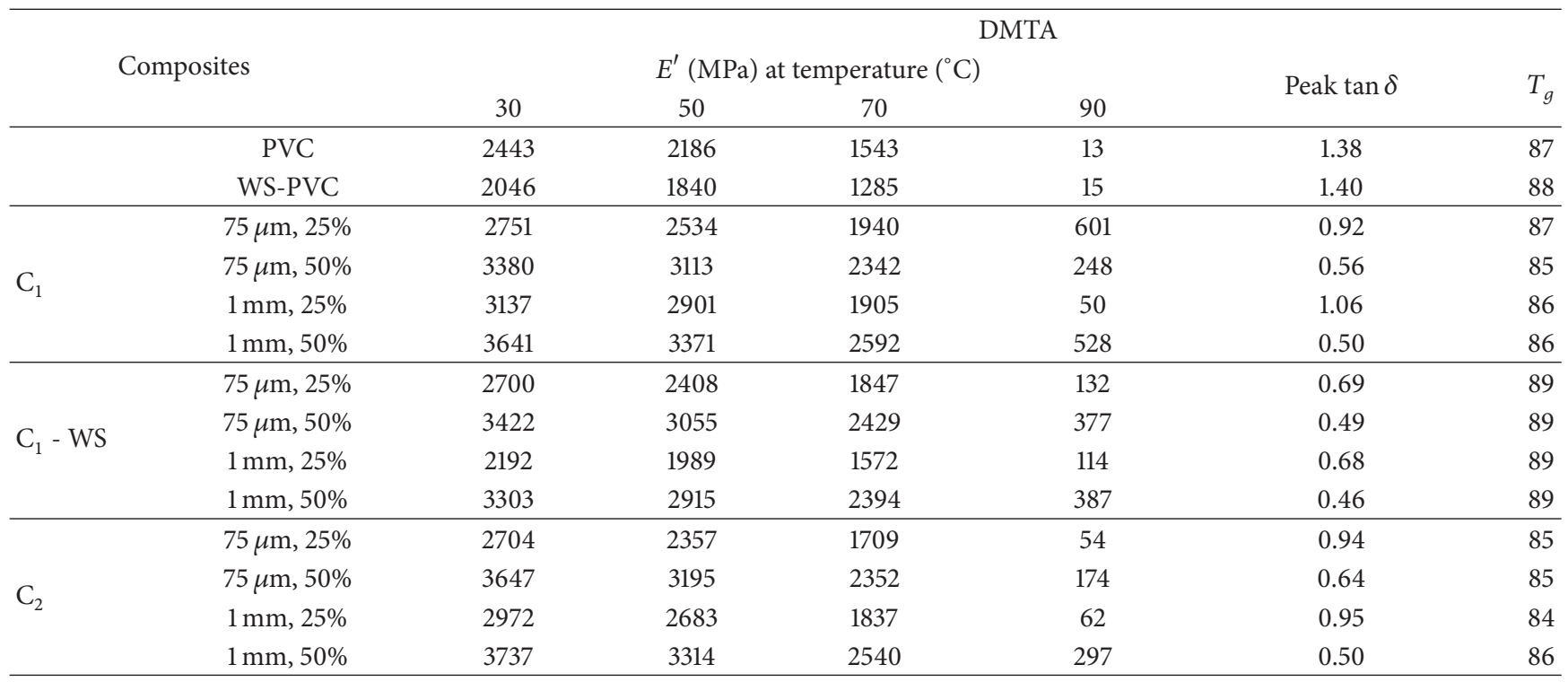

Note: WS = water soaked.

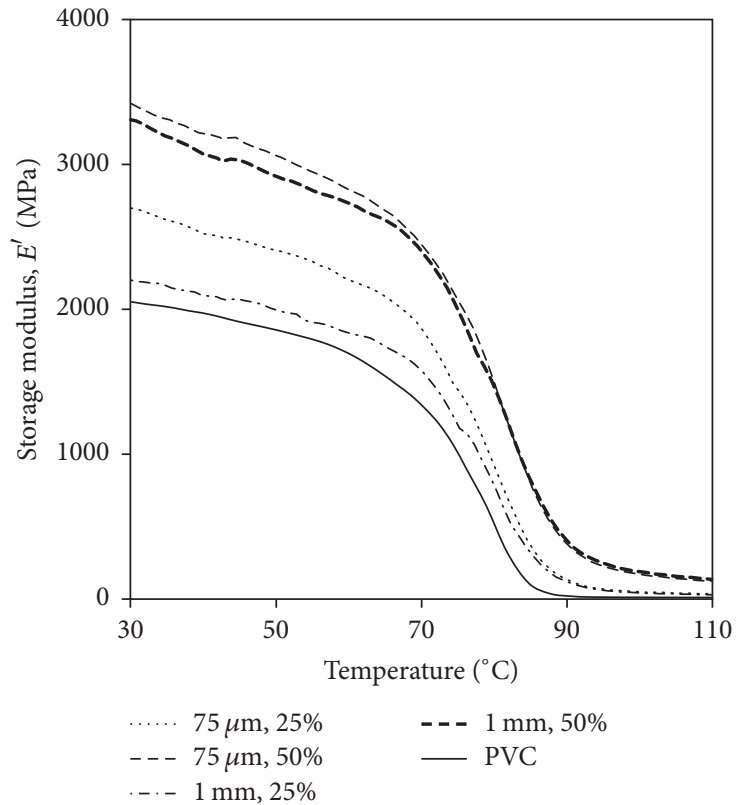

(a)

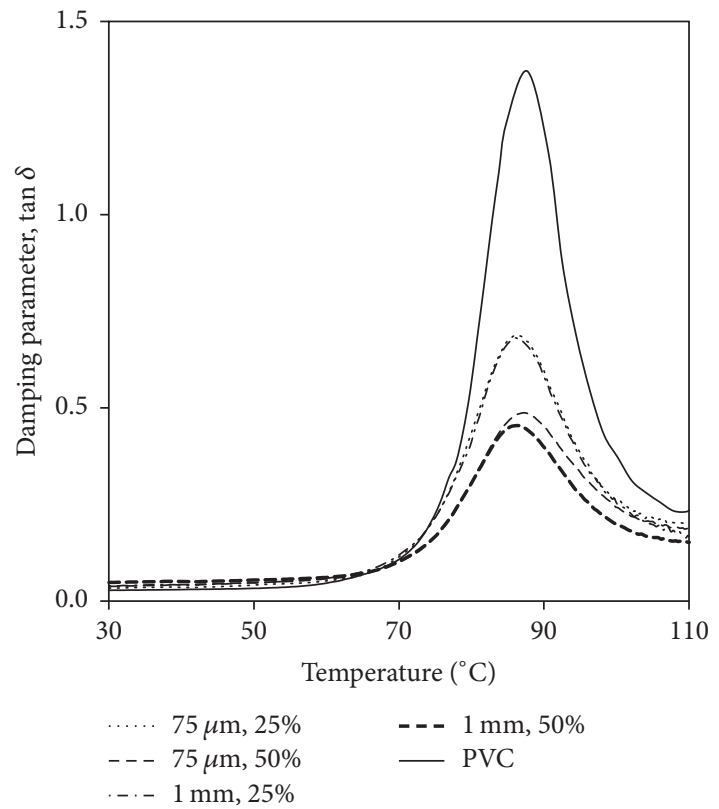

(b)

FIGURE 5: DMTA plots of water-soaked PVC/bamboo composites and water-soaked pure PVC composites using $\mathrm{C}_{1}$ : (a) storage modulus, $E^{\prime}$, and (b) $\tan \delta$.

and $\mathrm{C}_{2} \mathrm{PVC} /$ bamboo composites. This suggests the thermal properties of PVC in the composites were independent of the content of various processing lubricants used which was consistent with previous analyses of related PVC/bamboo composites [25]. In comparing the two bamboo particle sizes, DMTA revealed no clear trend between use of $1 \mathrm{~mm}$ and $75 \mu \mathrm{m}$ particles across the $\mathrm{C}_{1}$ and $\mathrm{C}_{2}$ composites and bamboo content.
DMTA of water-soaked PVC/bamboo composites revealed up to $30 \%$ lower $E^{\prime}$ values below $70^{\circ} \mathrm{C}$ when compared with original samples (Figure 5). This was consistent with ambient flexural testing (Table 2) and results for WPCs in which water immersion affects plasticization of wood components and contributes to fiber-matrix debonding [26]. However, above $70^{\circ} \mathrm{C}$, DMTA profiles of water-soaked composites were comparable to those of non-soaked samples. 
Within the water-soaked composite series, DMTA revealed that those samples with $<75 \mu \mathrm{m}$ particle size retained a higher $E^{\prime}$ compared to composites comprising $<1 \mathrm{~mm}$ particles. While the mechanism for this effect is uncertain, it is possible that the smaller particles and their packing arrangements and potential particle swelling have lesser effect on matrix interactions than the coarser fraction.

In considering the flexural properties of composites before and after water soaking, the PVC-bamboo composites achieve ASTM D 6662 minimum requirements. With static flexural modulus values of the original composites ranging between $c a .3800$ and $5100 \mathrm{MPa}$ and flexural rupture between ca. 35 and $60 \mathrm{MPa}$ (Figure 1), each PVC-bamboo composite exceeded ASTM D 6662 minimum values of 340 and 6.9 MPa, respectively. While composite performance was significantly reduced on water soaking, flexural modulus and rupture values of. 3400 and ca. $34 \mathrm{MPa}$, respectively, for the $25 \%$ bamboo content samples at water saturation still meet the minimum performance expected for exterior applications. Furthermore, the use of DMTA has revealed that the PVC/bamboo composites can retain these mechanical properties up to temperatures of $c a .70^{\circ} \mathrm{C}$. Additionally, with PVC having low moisture absorptivity ( $0.07 \%$ to $0.4 \%$ in $24 \mathrm{~h}$ ) and a high resistance to fungus/algae growth in composites [11], the outcomes of the present study suggest that these PVC/bamboo composites may be suited to both interior and exterior applications such as substituting for decking lumber products.

\section{Summary}

Flexural properties of PVC/bamboo composites under static and dynamic-thermal conditions have been evaluated by comparing differing bamboo particle sizes, $25 \%$ and 50\% bamboo particle loadings, and effects of water soaking. Results indicate that both bamboo particle loading and composite water soaking have the most impact on composite performance. Use of differing bamboo particle sizes $(<75 \mu \mathrm{m}$ and $<1 \mathrm{~mm}$ ) or processing lubricants led to relatively minor differences in composite properties. The use of bamboo particles led to significantly (>30\%) increased composite flexural properties which was similar to using wood particles in WPCs. The PVC/bamboo composite flexural properties were retained on heating up to PVC $T_{g}\left(c a .70^{\circ} \mathrm{C}\right)$ temperature. However, as with wood-filled composites such as WPCs, extended water soaking to full saturation led to $10 \%$ weight uptakes and reduced flexural properties of these composites. Nonetheless, overall, the flexural performance of $\mathrm{PVC} /$ bamboo composites, in their original form or saturated with water, achieves minimum ASTM D 6662 performance criteria and suggests the suitability of PVC/bamboo composites for both interior and exterior applications.

\section{Conflicts of Interest}

The authors declare that they have no conflicts of interest.

\section{References}

[1] I. Ghasemi and M. Farsi, "Interfacial behavior of wood plastic composite: effect of chemical treatment on wood fibers," Iranian Polymer Journal, vol. 19, no. 10, pp. 811-818, 2010.

[2] T. Ratanawilai, P. Lekanukit, and S. Urapantamas, "Effect of rubberwood and palm oil content on the properties of woodpolyvinyl chloride composites," Journal of Thermoplastic Composite Materials, vol. 27, no. 6, pp. 719-730, 2014.

[3] P. Chaowana, "An alternative raw material for wood and wood based composites," J Mater Sci Res, vol. 2, no. 2, pp. 90-102, 2013.

[4] A. Gupta and A. Kumar, "Potential of bamboo in sustainable development asia-pacific business review," Asia Pacific Business Review, vol. 4, no. 3, pp. 100-107, 2008.

[5] K. C. Buckingham, L. Wu, and Y. Lou, "Can't See the (Bamboo) Forest for the Trees: Examining Bamboo's Fit Within International Forestry Institutions," Ambio, vol. 43, no. 6, pp. 770-778, 2014.

[6] C. Clemons, In Wood-Polymer Composites, Woodhead Publishing Ltd., UK, 2008.

[7] J. Kassim, Properties of particleboard and particle-filled thermoplastic composite from bamboo (Gigantochloa Scortechinii). Doctoral dissertation [Doctoral, thesis], Universiti Putra Malaysia, Malaysia, 1999.

[8] S.-Y. Lee, S.-J. Chun, G.-H. Doh, I.-A. Kang, and K.-H. Paik, "Influence of chemical modification and filler loading on fundamental properties of bamboo fibers reinforced polypropylene composites," Journal of Composite Materials, vol. 43, no. 15, pp. 1639-1657, 2009.

[9] S. Kumar, V. Choudhary, and R. Kumar, "Study on the compatibility of unbleached and bleached bamboo-fiber with LLDPE matrix," J Therm Anal Calorim, vol. 102, pp. 751-761, 2010.

[10] S. Mohanty and S. K. Nayak, "Short bamboo fiber-reinforced HDPE composites: influence of fiber content and modification on strength of the composite," Journal of Reinforced Plastics and Composites, vol. 29, no. 14, pp. 2199-2210, 2010.

[11] C. C. Ibeh, Thermoplastic materials, Taylor and Francis Group; LLC, New York, NY, USA, 2011.

[12] J.-Y. Kim, J. H. Peck, S.-H. Hwang et al., "Preparation and mechanical properties of poly(vinyl chloride)/bamboo flour composites with a novel block copolymer as a coupling agent," Journal of Applied Polymer Science, vol. 108, no. 4, pp. 26542659, 2008.

[13] H. Wang, K. C. Sheng, T. Lan, M. Adl, X. Q. Qian, and S. M. Zhu, "Role of surface treatment on water absorption of poly(vinyl chloride) composites reinforced by Phyllostachys pubescens particles," Composites Science and Technology, vol. 70, no. 5, pp. 847-853, 2010.

[14] K. Sheng, S. Qian, and H. Wang, "Influence of potassium permanganate pretreatment on mechanical properties and thermal behavior of moso bamboo particles reinforced PVC composites," Polymer Composites, vol. 35, no. 8, pp. 1460-1465, 2014.

[15] T. C. Jennings and W. H. Starnes, "In PVC Handbook," E. W. Charles, W. S. James, and A. D. Charles, Eds., pp. 95-171, 2005.

[16] F. Mengeloglu, R. Kurt, D. J. Gardner, and S. O’Neill, “Mechanical properties of extruded high density polyethylene and polypropylene wood flour decking boards," Iran Polym J, vol. 16, no. 7, pp. 477-487, 2007.

[17] S. A. Bahari and A. Krause, "Utilizing Malaysian bamboo for use in thermoplastic composites," Journal of Cleaner Production, vol. 110, pp. 16-24, 2016. 
[18] M. Müller, A. Gellerich, H. Militz, and A. Krause, "Resistance of modified polyvinyl chloride/wood flour composites to basidiomycetes," European Journal of Wood and Wood Products, vol. 71, no. 2, pp. 199-204, 2013.

[19] M. Sain and M. Pervaiz, In Wood-Polymer Composites, Woodhead Publishing Ltd., UK, 2008.

[20] H. P. S. A. Khalil, M. A. Tehrani, Y. Davoudpour, A. H. Bhat, M. Jawaid, and A. Hassan, "Natural fiber reinforced poly(vinyl chloride) composites: A review," Journal of Reinforced Plastics and Composites, vol. 32, no. 5, pp. 330-356, 2013.

[21] M. J. Zaini, M. Y. A. Fuad, Z. Ismail, M. S. Mansor, and J. Mustafah, "The effect of filler content and size on the mechanical properties of polypropylene/oil palm wood flour composites," Polymer International, vol. 40, no. 1, pp. 51-55, 1996.

[22] M. Kociszewski, C. Gozdecki, A. Wilczyński, S. Zajchowski, and J. Mirowski, "Effect of industrial wood particle size on mechanical properties of wood-polyvinyl chloride composites," European Journal of Wood and Wood Products, vol. 70, no. 1-3, pp. 113-118, 2012.

[23] C. Deo and S. K. Acharya, "Effect of moisture absorption on mechanical properties of chopped natural fiber reinforced epoxy composite," Journal of Reinforced Plastics and Composites, vol. 29, no. 16, pp. 2513-2521, 2010.

[24] H. N. Dhakal, Z. Y. Zhang, and M. O. W. Richardson, "Effect of water absorption on the mechanical properties of hemp fibre reinforced unsaturated polyester composites," Composites Science and Technology, vol. 67, no. 7-8, pp. 1674-1683, 2007.

[25] S. A. Bahari, W. J. Grigsby, and A. Krause, "Thermal stability of processed PVC/bamboo blends: Effect of compounding procedures," European Wood and Wood Products Journal, vol. 75, no. 2, pp. 147-159, 2017.

[26] S. K. Najafi, M. Mostafazadeh-Marznaki, and M. Chaharmahali, "Effect of Thermo-Mechanical Degradation of Polypropylene on Hygroscopic Characteristics of Wood Flour-Polypropylene Composites," Journal of Polymers and the Environment, vol. 18, no. 4, pp. 720-726, 2010. 

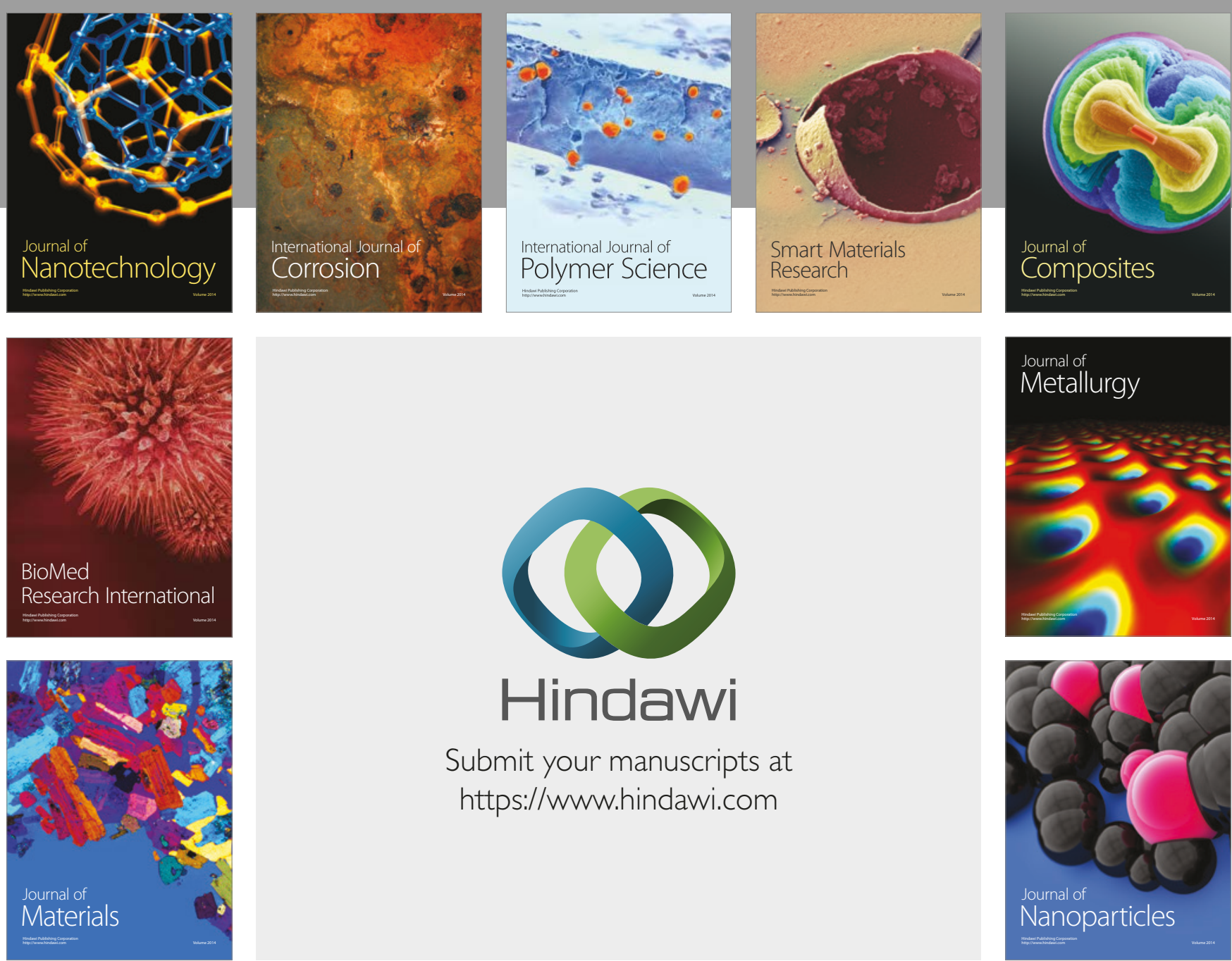

\section{Hindawi}

Submit your manuscripts at

https://www.hindawi.com
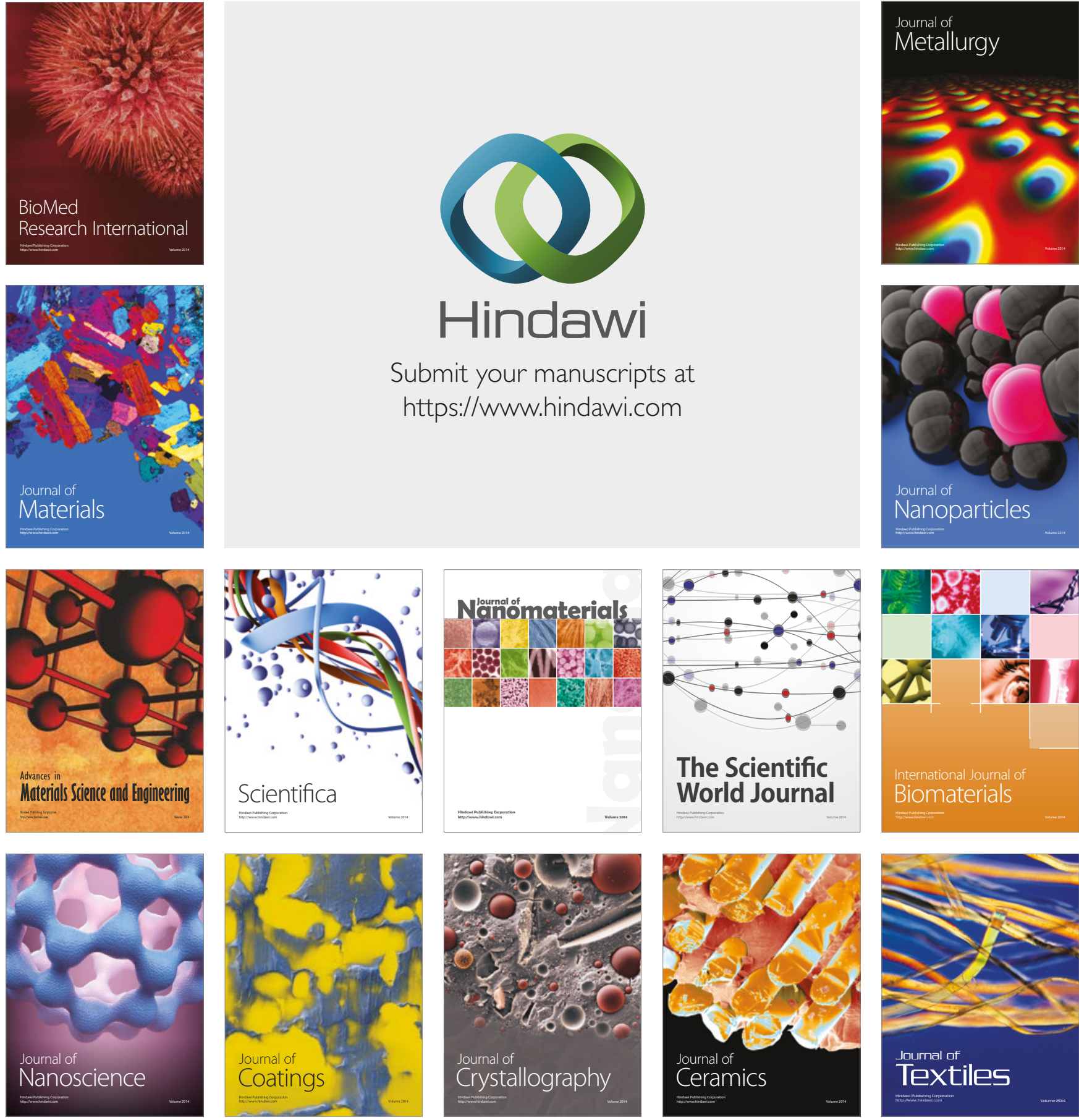

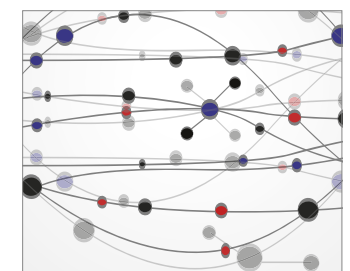

The Scientific World Journal
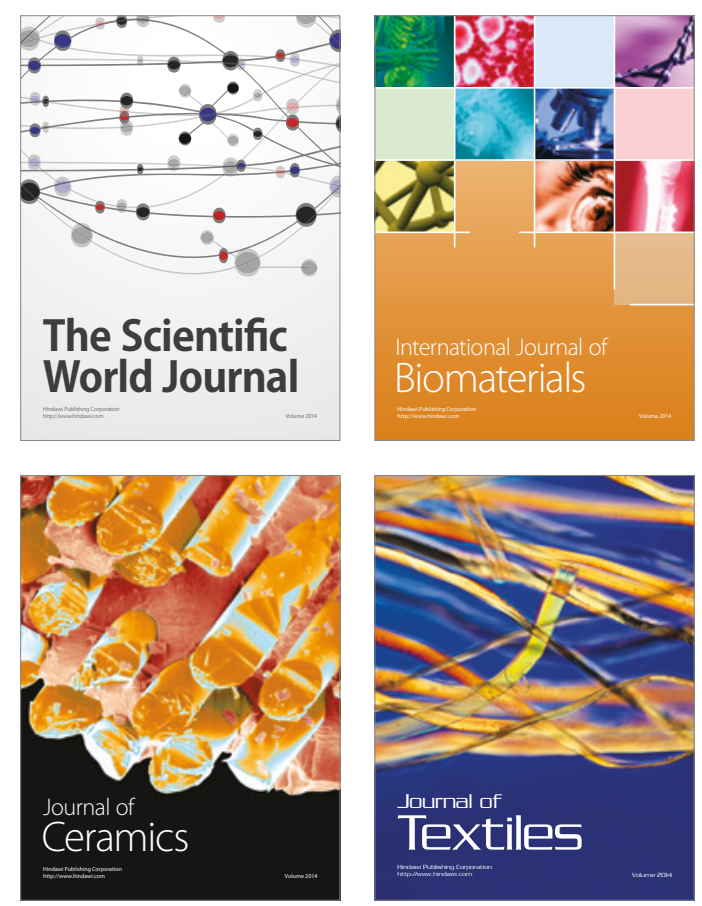